\title{
Analisis Perbandingan Kehilangan Prategang Akibat Variasi Letak Tendon PC I Girder Jembatan Beton Prategang
}

\author{
Ibham Yamin ${ }^{1}$, Siswanti Zuraida ${ }^{1}$, Ilham ${ }^{1}$ \\ Teknik Sipil, Fakultas Teknik, Institut Teknologi Sains Bandung, Cikarang, Indonesia \\ ibhamyamin@gmail.com
}

Informasi naskah:

Diterima

15 Juli 2020

Direvisi

17 Agustus 2020

Disetujui terbit

20 Agustus 2020

Diterbitkan

31 Agustus 2020

\begin{abstract}
Prestressed force loss always occurs in prestressed concrete (loss prestressed). The most common form used in pre-tensile beams is straight tendons and for post-tensile beams are curved tendons. In planning a prestressed concrete bridge structure, the loss of prestressed force must be considered, because the stress on the prestressed concrete tendon decreases continuously over time. The number of factors that are interrelated, for the effectiveness of the design, location of tendons along the spans need to be considered, so that the tensile strength that occurs in the extreme fiber beam is limited or none at all in the cross section. This final project will examine the shape of the PC beam I Girder with 4 tendon setting conditions namely straight tendon cable which is on the neutral axis so that the eccentricity $=0$ (condition 1$)$, straight tendon cable which is at $1 / 6 \mathrm{~h}$ so that the eccentricity $\neq 0$ (condition 2 ), tendon cable with draped / parabolic shape (condition 3), and tendon condition with harped shape (condition 4). The biggest prestressed loss results were PC I Girder (condition 2) $=395.81 \mathrm{MPa}$ (26.07\%), while the smallest prestressed loss is PC I Girder (condition3) $=367.44 \mathrm{MPa}$ $(24.2 \%)$. Condition 1 and 2 in girder is not suitable for use because it exceeds the value of the allowable stress at the limit of prestressed and deflection permits on girder are safe for each condition.
\end{abstract}

Keywords: loss of prestressed, tendon variation, tension control, deflection control

\section{PENDAHULUAN}

Jembatan beton prategang merupakan fasilitas penghubung berpindahnya manusia dari tempat asal ke tempat tujuan dimana di antara kedua tempat tersebut terdapat rintangan yang menggunakan beton prategang pada strukturnya ${ }^{1)}$. Bangunan struktural pada jembatan beton prategang terdiri dari tiang pancang, pile cap, kolom, pier head, Girder dan slab lantai kerja ${ }^{2)}$. Kemampuan sebuah jembatan beton prategang sangat dipengaruhi oleh 
kekuatan Girdernya yang menurut sistem perancangannya Girder terdiri dari dua jenis Girder precast dan on site Girder ${ }^{3}$. Girder memiliki banyak bentuk di antaranya PC I Girder, PC U Girder, box Girder dan voided slab dimana setiap bentuk memiliki kelebihan dan kekurangan masing-masing ${ }^{4)}$.

Penelitian ini menggunakan Precast Concrete I Girder. Beton prategang adalah beton yang mengalami tegangan internal dengan besar (akibat stressing) dan distribusi sedemikian rupa sehingga dapat mengimbangi sampai batas tertentu tegangan yang terjadi akibat beban eksternal ${ }^{5}$. Pekerjaan penting dilakukan pada Girder adalah proses stressing yang merupakan proses penarikan kabel tendon yang ada di dalam Girder untuk menjadikan Girder sebagai beton prategang. Pemberian tegangan pada stressing dapat dilakukan dengan dua sistem, sistem pratarik (pre-tension) dan pasca tarik (post-tension) ${ }^{6}$. Tendon lurus banyak digunakan pada balok pracetak, sedangkan penggunaan tendon lengkung lebih umum digunakan pada elemen pascatarik ${ }^{7)}$. Pemberian tegangan pada beton prategang mengakibatkan kehilangan gaya prategang (loss prestressed) ${ }^{8}$. Dalam perencanaan struktur jembatan beton prategang kehilangan gaya prategang harus dipertimbangkan, karena tegangan pada tendon beton prategang berkurang secara kontinu seiring berjalannya waktu ${ }^{9)}$. Kehilangan gaya prategang dalam tendon untuk setiap waktu harus diambil sebagai jumlah dari kehilangan seketika dan kehilangan yang tergantung waktu, baik dalam jangka pendek maupun jangka Panjang ${ }^{10)}$. Kehilangan gaya prategang adalah berkurangnya gaya yang bekerja pada tendon pada tahap-tahap pembebanan. Secara umum kehilangan gaya prategang dapat dijelaskan sebagai berikut ${ }^{11)}$ :

1. Immediate Elastic Losses, yaitu kehilangan gaya prategang langsung atau segera setelah beton diberi gaya prategang. Kehilangan gaya prategang secara langsung ini disebabkan oleh perpendekan elastis beton, kehilangan akibat friksi atau geseran sepanjang kelengkungan dari tendon, ini terjadi pada beton prategang dengan sistem post tension, dan kehilangan pada sistem angkur, antara lain akibat slip diangkur.

2. Time Dependent Losses, yaitu kehilangan gaya prategang akibat dari pengaruh waktu, yang mana hal ini disebabkan oleh rangkak (creep), susut pada beton, dan pengaruh temperature dan relaksasi baja/kabel prategang.

Keefektifan desain letak tendon di sepanjang bentang perlu diperhatikan karena banyaknya faktor yang saling terkait, sebagai contoh tegangan tarik yang terjadi di serat ekstrim balok sangat terbatasnya atau tidak ada sama sekali di penampang. Total kehilangan gaya prategang harus relatif lebih kecil dibandingkan gaya prategang yang bekerja sehingga perlu dilakukan analisis mengenai kehilangan gaya prategang yang terjadi. Oleh sebab itu penelitian ini menganalisis perbandingan kehilangan prategang akibat variasi letak tendon PC I Girder jembatan beton prategang. 


\section{METODE}

\subsection{Data Perencanaan}

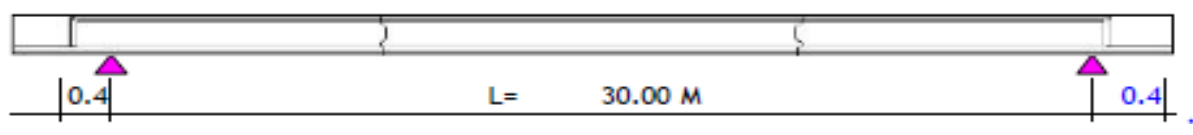

Gambar 1. Bentang balok prategang

Tabel 1. Data prategang

\begin{tabular}{lcc}
\hline Keterangan & Notasi & Dimensi (mm) \\
\hline Panjang total & $\mathrm{L}$ & 30000 \\
Jarak antar girder $\mathrm{I}$ & $\mathrm{S}$ & 2000 \\
Jarak antar girder $\mathrm{U}$ & $\mathrm{S}$ & 3000 \\
Bentang slab Box & $\mathrm{S}$ & 4000 \\
Tebal slab lantai & Ho & 220 \\
Tebal aspal & Ha & 50 \\
\hline
\end{tabular}

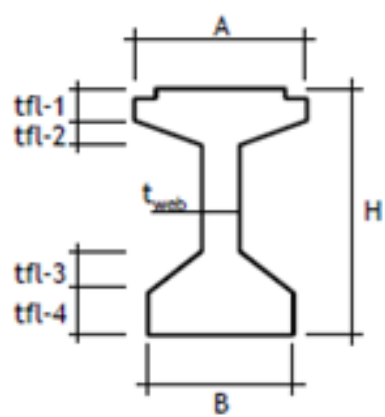

Gambar 2. PC I girder

Tabel 2. Dimensi PC I girder

\begin{tabular}{cccc}
\hline Kode & Dimensi $(\mathrm{mm})$ & Kode & Dimensi $(\mathrm{mm})$ \\
\hline H & 1700 & tfl-1 & 200 \\
A & 800 & tfl-2 & 120 \\
B & 700 & tfl-3 & 250 \\
Tweb & 200 & tfl-4 & 250 \\
\hline
\end{tabular}

Untuk jembatan prategang pada girder menggunakan mutu beton K-500. Dari analisis mutu balok prategang didapatkan hasil sebagai berikut:

Kuat tekan beton prategang (fc') $=41.5 \mathrm{Mpa}$

Kuat Tekan beton pada keadaan awal (fci') $\quad=80 \%$ fc'

Modulus elastic beton (Ec)

$$
\begin{aligned}
& =33.2 \mathrm{Mpa} \\
& =4700 \sqrt{ }\left(\mathrm{fci}{ }^{\prime}\right) \\
& =30277.6 \mathrm{Mpa}
\end{aligned}
$$




\subsection{Model Variasi Tendon}

Berikut kondisi - kondisi letak tendon:

1. Kabel tendon lurus ditempatkan berada pada sumbu netral sehingga eksentrisitas $=0$.

2. Kabel tendon lurus ditempatkan berada pada $1 / 6 \mathrm{~h}$ sehingga eksentrisitas $\neq 0$.

3. Kabel tendon memiliki lintasan berbentuk draped (parabola).

4. Kondisi tendon memiliki lintasan berbentuk harped.

\subsection{Prosedur penelitian}

Langkah-langkah dalam penelitian yang akan dilakukan sebagai berikut:

1. Menentukan data struktur jembatan dan profil girder.

2. Menghitung analisis penampang girder.

3. Menghitung pembebanan pada jembatan.

4. Menghitung kehilangan prategang akibat variasi tendon.

5. Menghitung kontrol tegangan dan lendutan

6. Menyimpulkan bagaimana perbandingan kehilangan prategang akibat variasi tendon.

\section{PEMBAHASAN DAN DISKUSI}

\subsection{Analisis Penampang}

Analisis penampang dibutuhkan untuk mengetahui luas, titik berat, momen inersia dan modulus section pada balok, baik balok precast maupun balok komposit ${ }^{12)}$. Analisis penampang pada PC I girder dapat dilihat pada Tabel 3.

Tabel 3 Analisis penampang

\begin{tabular}{lcc}
\hline \multirow{2}{*}{ Ket } & \multicolumn{2}{c}{ PC I Gider } \\
\cline { 2 - 3 } & Balok Precast & Komposit \\
\hline $\mathrm{A}\left(\mathrm{m}^{2}\right)$ & 0.6695 & 0.9325 \\
$\mathrm{Yb}(\mathrm{m})$ & 0.8166 & 1.094 \\
$\mathrm{Ya}(\mathrm{m})$ & 0.8834 & 0.806 \\
$\mathrm{I}\left(\mathrm{m}^{4}\right)$ & 0.2364 & 0.4199 \\
$\mathrm{Wa}\left(\mathrm{m}^{3}\right)$ & 0.2676 & 0.5209 \\
$\mathrm{~Wb}\left(\mathrm{~m}^{3}\right)$ & 0.2895 & 0.3838 \\
\hline
\end{tabular}

\subsection{Pembebanan pada Jembatan}

Balok girder merupakan komponen struktur yang menerima beban kombinasi, baik beban mati, beban hidup, gaya rem, beban angin dan beban gempa ${ }^{13)}$. Kombinasi pembebanan pada PC I girder dapat dilihat Tabel 4.

Tabel 4 Pembebanan pada jembatan

\begin{tabular}{lccc}
\hline \multirow{2}{*}{ Jenis Beban } & \multirow{2}{*}{ Kode } & \multicolumn{2}{c}{ PC I Gider } \\
\cline { 3 - 4 } & & Komb1 & Komb2 \\
\hline Beban sendiri & MS & 3647.17 & 3647.17 \\
Beban mati tamb & MA & 357.75 & 357.75 \\
Beban lajur & TD & 3054 & 3054 \\
\hline
\end{tabular}




\begin{tabular}{lccc}
\hline Gaya rem & TB & 35.70 & 35.70 \\
Beban angin & EW & 330.75 & - \\
Beban gempa & EQ & - & 574 \\
\hline Jumlah $(\mathrm{kNm})$ & MU & 7425.37 & 7668.62 \\
\hline
\end{tabular}

\subsection{Gaya Prategang}

Jenis kabel yang digunakan adalah uncoated 7 wire super strands, ASTM A-416 ${ }^{14)}$ grade 270 dengan spesifikasi diameter standar 1,27 cm, modulus elastisitas $193000 \mathrm{Mpa}$ dan effective section area (Ast) 0,987 cm2. Gaya prategang pada PC I girder dapat dilihat pada Tabel 5.

Tabel 5 Gaya prategang

\begin{tabular}{llcccc}
\hline Keterangan $(\mathrm{PC}$ I Girder) & Kode & Kond1 & Kond2 & Kond3 & Kond4 \\
\hline Jenis tendon & - & Lurus & Lurus & Draped & Harped \\
Titik berat tendon $(\mathrm{m})$ & Zo & 0.8166 & 0.28 & 0.135 & 0.125 \\
Eksentrisitas tendon $(\mathrm{m})$ & Es & 0 & 0.5333 & 0.6816 & 0.6916 \\
Gaya prategang awal $(\mathrm{kN})$ & $\mathrm{Pt}$ & 4441.52 & 7960.83 & 6813.82 & 6580.37 \\
Teg. pada penampang $(\mathrm{MPa})$ & Fcir & 6.634 & 11.89 & 10.17 & 9.82 \\
Teg. pada pusat berat $(\mathrm{MPa})$ & Fcds & 1.236 & 1.205 & 1.541 & 1.563 \\
Jumlah strand yang dibutuhkan & $\mathrm{ns}$ & 30 & 52 & 44 & 44 \\
G.prategang akibat jacking $(\mathrm{kN})$ & $\mathrm{Pj}$ & 4622.01 & 8284.35 & 7090.73 & 6847.79 \\
\hline
\end{tabular}

Kehilangan prategang membutuhkan data-data sebagai berikut.

Momen akibat berat sendiri balok (Mbs)

Mbs PC I = 1920.628 kNm;

Jumlah tendon yang direncanakan (nt)

nt $\mathrm{PC} \mathrm{I}=4$;

Koefisien kelengkungan $(\mu)$ dan sudut $(\alpha)$;

$\mu$ kond $1=0 ; \quad$ kond $2=0 ; \quad$ kond $3=0.2 ; \quad$ kond $4=0.25$.

$\alpha$ kond $1=0 ; \quad$ kond $2=0 ; \quad$ kond $3=0.1 ; \quad$ kond $4=0.1$.

Koefisien rangkak pasca tarik $\left(\mathrm{K}_{\mathrm{cr}}\right)=1.6$ untuk pascatarik ${ }^{19)}$.

Nilai faktor relaksasi $\mathrm{C} \quad=0.75$;

Nilai koefisien relaksasi $\left(\mathrm{K}_{\mathrm{RE}}\right) \quad=138 \mathrm{MPa}$;

Nilai faktor waktu $(\mathrm{J}) \quad=0.15$.

Panjang slip $(\Delta \mathrm{a}) \quad=3 \mathrm{~mm}$

Untuk tendon type 7 wire strand pada selongsong yang fleksibel, harga koefisien wobble $\mathrm{K}=0,0016 \sim 0.0066^{18)}$. koefisien wobble $\mathrm{K}$;

w kond $1=0.004 ; \quad$ kond $2=0.002$;

kond $3=0.002 ; \quad$ kond $4=0.002$. 


\subsection{Kehilangan Prategang}

Kehilangan prategang dapat berupa proses menurunnya tegangan prategang dapat diakibatkan oleh mutu beton dan letak tendonnya. Berikut grafik yang dihasilkan setiap kondisi pada girder.

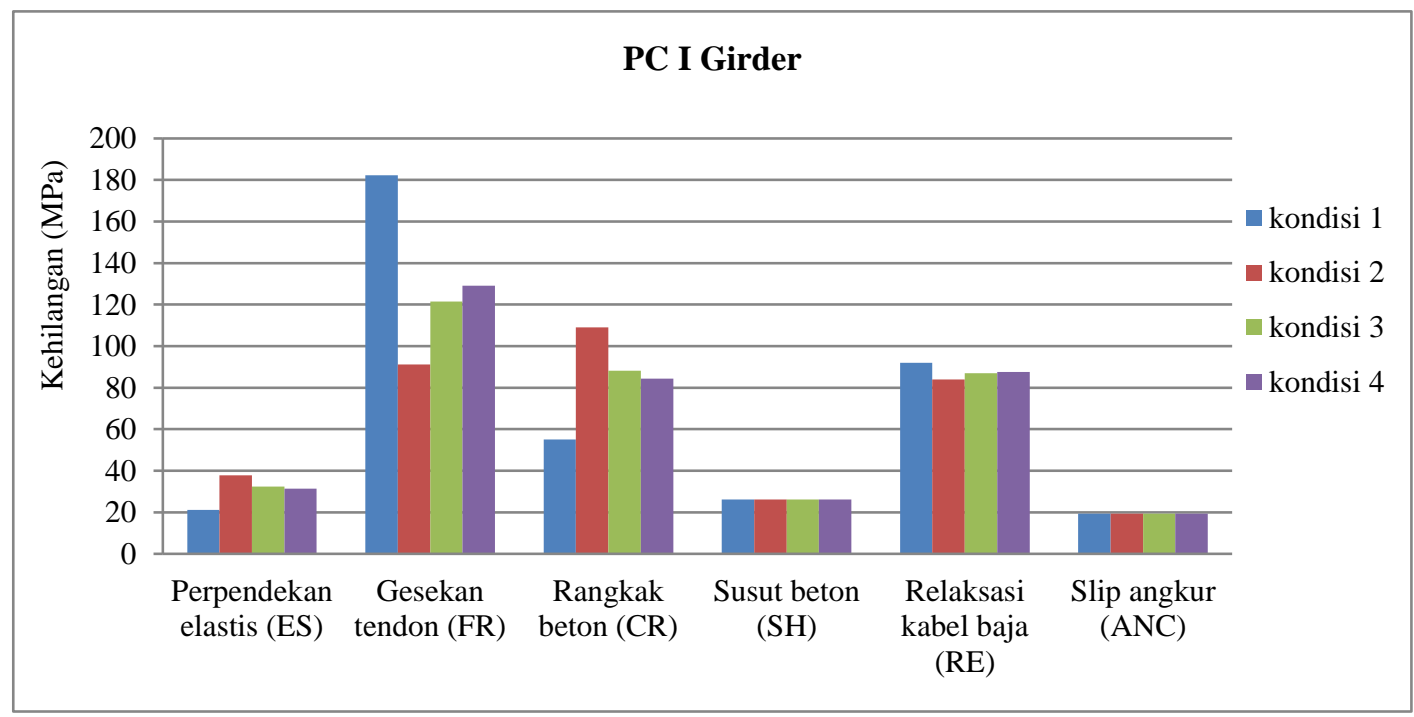

Gambar 3 Grafik kehilangan prategang

Perbandingan pada jenis kehilangan perpendekan elastis (ES) terbesar terjadi pada kondisi $2(\mathrm{PC} \mathrm{I}=37.89 \mathrm{MPa}$ ) dikarenakan nilai tegangan pada penampang beton yang besar. Hal ini berpengaruh terhadap nilai rangkak pada beton (CR) yang besar juga terjadi pada kondisi 2 (PC I = 108.98 MPa) karena deformasi adanya tegangan pada penampang beton sebagai fungsi dari waktu ${ }^{20)}$. Perbandingan susut pada beton $(\mathrm{SH})$ memiliki nilai yang sama pada setiap kondisi Sebesar 26.132 MPa dikarenakan kuat tekan beton yang digunakan sama sehingga menghasilkan modulus elastisitas beton yang sama, lalu tendon baja mengalami perpanjangan tergantung pada lamanya waktu berjalan dan nilai tegangan yang ada serta dihambat juga oleh besaran perpendekan elastis (ES) sehingga diperoleh nilai Relaksasi kabel baja (RE) yang terbesar pada kondisi 1 (PC I = $91.98 \mathrm{MPa}$ ). Gesekan tendon (FR) terbesar terjadi pada kondisi 1 (PC I = $182 \mathrm{MPa}$ ) terjadi karena pengaruh pergerakan dari selongsong yang di letakkan secara konsentris maka timbul koefisien yang besar ${ }^{15)}$ dan nilai slip angkur (ANC) memiliki nilai yang sama pada setiap kondisi pada girder sebesar 19.3 MPa dikarenakan jenis strand (Uncoated stress relieve seven wires strand ASTM A416 Grade 270 Low Relaxation) dan nilai elastisitas beton yang digunakan sama. Berikut grafik total kehilangan prategang PCI girder. 


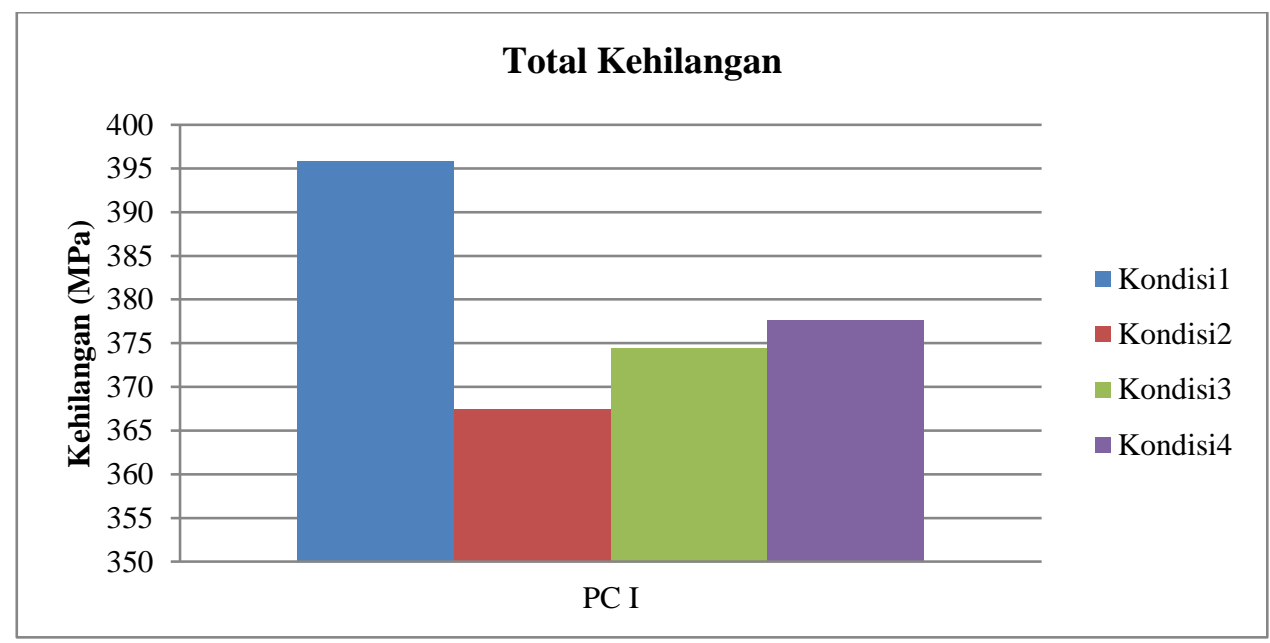

Gambar 4 Grafik total kehilangan

Gaya prategangan akan mengalami kehilangan prategangan sehingga gaya pratekan yang diperlukan untuk desain menggunakan tegangan pratekan efektif, yakni nilai tegangan prategang yang sudah memperhitungan besarnya kehilangan prategangan ${ }^{16)}$. Hasil total kehilangan prategang terbesar adalah PC I girder (kondisi2) $=395.81 \mathrm{MPa}$ $(26.07 \%)$, sedangkan kehilangan prategang terkecil adalah PC I girder (kondisi3) $=367.44$ $\operatorname{MPa}(24.2 \%)$.

\subsection{Kontrol Tegangan dan Lendutan}

Kontrol tegangan izin dan lendutan pada masing-masing girder dapat dilihat pada Tabel 6 dan Tabel 7.

Tabel. 6 Kontrol Tegangan Ijin

\begin{tabular}{lcccccc}
\hline \multirow{2}{*}{ Kontrol tegangan } & \multicolumn{5}{c}{ PC I Girder } & Tegangan \\
& \multirow{2}{*}{ Kondisi 1 } & Kondisi 2 & Kondisi 3 & Kondisi 4 & izin (MPa) \\
\hline Sesaat setelah & Atas & -13.06 & -3.44 & -0.56 & -0.59 & 2.88 \\
penegangan & Bawah & 0.74 & -18.3 & -17.53 & -16.8 & 19.92 \\
Pada saat & Atas & -16.17 & -7.93 & -5.44 & -5.45 & 18.86 \\
layan & Bawah & 14.87 & -0.96 & -0.57 & 0.005 & 3.22 \\
\hline
\end{tabular}

Kondisi 1 dan 2 melampaui tegangan izin pada serat atas 13.06 dan $3.44>2.88 \mathrm{MPa}$ yang diizinkan pada saat transfer. Kondisi 1 pada saat semua beban diperhitungkan $14.87>$ 3.22 MPa, sehingga kondisi 1 dan 2 tidak cocok digunakan untuk perencanaan jembatan beton prategang pascatarik I girder. Tegangan kerja dari suatu komponen struktur jembatan pada grafik yang melampaui nilai tegangan yang diijinkan sehingga berpotensi mengakibatkan keretakan pada komponen beton dan tegangan yang berlebihan pada seratserat atas dari gelagar sehingga mengakibatkan keruntuhannya ${ }^{17)}$. Kondisi 3 dan 4 bisa digunakan meski kondisi 2 mempunyai nilai kehilangan prategang yang lebih kecil dari semua kondisi di PC I girder. Pada RSNI T-12-2004 Perencanaan struktur beton untuk jembatan, lendutan akibat beban rencana untuk daya layan pada Peraturan Pembebanan 
untuk Jembatan Jalan Raya tidak melampaui 1/250 bentang. Berikut hasil seluruh lendutan yang terjadi pada girder.

Tabel 7 Kontrol Lendutan

\begin{tabular}{lccccc}
\hline \multirow{2}{*}{ Kontrol lendutan } & \multicolumn{4}{c}{ PC I Girder } & Lendutan izin \\
& Kond 1 & Kondisi 2 & Kondisi 3 & Kondisi 4 & $(\mathrm{mm})$ \\
\hline Kondisi awal & -47.76 & 10.09 & 15.53 & 14.25 & 120 \\
Kondisi akhir & -51.46 & -26.77 & -24.61 & -25.22 & 120 \\
Keterangan & OK & OK & OK & OK & ---- \\
\hline
\end{tabular}

Hasil kontrol lendutan menunjukkan seluruh kondisi pada setiap girder aman tidak melampaui $1 / 250$ bentang yaitu $120 \mathrm{~mm}$. Lendutan terkecil beton pada kondisi beban layan (setelah memperhitungkan semua kehilangan tegangan) PC I girder $=$ kondisi $3(-$ $24.61 \mathrm{~mm}$ ) lendutan terbesar pada girder dihasilkan oleh kondisi 1.

\section{KESIMPULAN}

Variasi tendon pada beton prategang pasca tarik berpengaruh pada kehilangan prategang khususnya pada kehilangan prategang akibat gesekan pada tendon. Variasi tendon yang ada; kondisi 3 (Draped) menghasilkan kehilangan prategang lebih kecil pada girder. Kehilangan prategang terbesar terjadi pada kondisi 1 (Lurus e $=0$ )

\section{UCAPAN TERIMA KASIH}

Penulis mengucapkan terimakasih kepada:

1) Ibu Siswanti Zuraida., MT. selaku Dosen Pembimbing I Tugas Akhir Program Studi Teknik Sipil Institut Teknologi dan Sains Bandung.

2) Bapak Ilham., MT. selaku Dosen Pembimbing II Tugas Akhir Program Studi Teknik Sipil Institut Teknologi dan Sains Bandung.

\section{DAFTAR PUSTAKA}

1) H.J Struyk, K.H.C.W Van Der Hen, dan Soemargono. (1990). Jembatan. Penerbit: Pradnya Paramita. Jakarta.

2) Raju, N. Krishna. (1988). Beton Prategang Edisi Kedua. Penerbit : Erlangga. Jakarta. 477 hlm.

3) Budiadi, Andri. (2008). Desain Praktis Beton Prategang. Penerbit: Penerbit Andi. Yogyakarta. $498 \mathrm{hlm}$.

4) SNI 1725:2016. (2016). Pembebanan untuk Jembatan. Badan Standardisasi Nasional. Jakarta.

5) Lin, T.Y. dan Burns, Ned. H. (2000). Desain Struktur Beton Prategang Edisi Ketiga. Penerbit : Binarupa Aksara. Jakarta. 411 hlm.

6) SNI 2847:2013. (2013). Persyaratan Beton Struktural untuk Bangunan Gedung. Badan Standardisasi Nasional. Jakarta.

7) Nawy, Edward. G. (2001). Beton Prategang Suatu Pendekatan Mendasar Edisi Ketiga. Penerbit : Erlangga. Jakarta. 452 hlm. 
8) Pricilia. (2016). Analisa Prestress Metode Post Tension Pada Balok Proyek Supermall Pakuwon Indah Phase-3 Surabaya (Skripsi). Surabaya: Universitas Narotama Surabaya.

9) Prestressed Concrete Institute. (2004). PCI Design Handbook 6th Edition. Prestressed Concrete Institute, Chicago.

10) RSNI T-12-2004. (2004). Perencanaan Struktur Beton untuk Jembatan. Badan Standardisasi Nasional. Jakarta.

11) Soetoyo. (2015). Konstruksi Beton Pratekan. Penerbit : Gunadharma. Jakarta.

12) Indra. (2015). Studi Perencanaan Jembatan Kali Surabaya Pada Akses Tol Sumo Dengan Balok Beton Pratekan Tipe I Girder. Jurnal Rekayasa Sipil, 3(2), 70-84.

13) Armin H.Manalip dan Banu D. Handono. (2018). Perencanaan Balok Girder Profil I pada Jembatan Prestressed dengan Variasi Bentang. Jurnal Sipil Statik, 6(2), 6774.

14) ASTM A 416., Standard Specification for Steel Strand, Uncoated Seven-Wire for Prestressed Concrete

15) Yunalia dan Bastya. (2017). Studi Perbandingan Penggunaan Pcu Girder Dan Pci Girder Pada Struktur Atas Jembatan Jurang Gempal, Wonogiri (Skripsi). Yogyakarta: Universitas Islam Indonesia

16) Priyono. (2018). Pengaruh Beban Gempa pada Struktur Atas Jematan Jalan Raya dengan I-Girder Beton Prategang Apabila Terjadi Ketidakpastian Prediksi Kehilangan Prategang. Jurnal Rekayasa Sipil dan Lingkungan, 2(2), 131-140.

17) Dini Fitria Annur dan Johannes Tarigan. (2013). Perencanaan Precast Concrete I Girder pada Jembatan Prestressed Post-tension dengan Bantuan Program Microsoft Office Excel (Skripsi). Medan: Universitas Sumatera Utara.

18) Christopher dan Theresa. (2004). A Probabilistic Comparison of Prestress Loss Methods in Prestressed Concrete Beams. PCI Journal, 49 (5), 52-69.

19) Ilham Noer, (2008). Perhitungan Balok Prategang (Pci - Girder) - Jembatan Srandakan Kulon Progo D.I. Yogyakarta. Penerbit: MNI-EC. Yogyakarta.

20) Rizkia, R. Selvia. (2017). Analisis Perbandingan Kehilangan Prategang Akibat Metode Stressing Satu Arah Dan Dua Arah Pada Jembatan Beton Prategang (Skripsi). Bandar Lampung: Universitas Lampung. 